\title{
Intelligent Vehicle Scrutiny to Eradicate Malversation
}

\author{
Suthanthara Raja PushpaJ ${ }^{\mathrm{a}, 1}$ Valarmathi $\mathrm{K}^{\mathrm{b}}$ \\ ${ }^{a, 1}$ PG Scholar, Dept of CSE, Panimalar Engineering College, Chennai \\ ${ }^{b}$ Professor, Dept of CSE, Panimalar Engineering College, Chennai
}

\begin{abstract}
In this modern world, there is an increasing crisis in monitoring the safety measures in the traffic field. Though there are many methods and techniques developed to find a solution to this particular problem, there is an empty or faulty field which each and every one tried to cover at each of their findings. One such problem is the malversation. This plays the major role in the traffic field through which the public who don't have enough driving experience, alcohol consumer and those who park their vehicle in no parking area which lead to the congestion and many other facts have been roaming freely without any fear causing disturbance to the public. Even the cops who are responsible for the safety of public and to monitor the traffic with full dedication they allow the criminals to flew away by getting bribes. So, in order to terminate this system, there is an urgent need to find an appropriate solution in this fields. Our paper has been proposed with this problem statement as their main goal and developed a system in Internet of things.
\end{abstract}

Keywords. IOT, Malversation, Congestion, No parking area, Cops, Police etc.

\section{Introduction}

Internet of things is one of the most adopted technique in all the fields as they are user friendly and can be maintained at regular intervals of time at low cost. Internet of things is the connection of number of objects to the network. Any system that reduces the workload of human kind is the Internet of Things. These objects can be simple in structure or be more complexed to crack it. It depends on the platform for which use they are being developed. Several papers and articles have been coming into existence to improve the features of several methodology. Though they have numerous solution they all have some defects in common to all the systems.Accuracy of the system plays the vital role in determining the quality of the system. Numerous papers have taken into consideration in literature survey learning about many methods. But no methods have a perfect hundred accuracy. Methods like SVM (Support Vector Machine) and Image Processing have been adopted by many authors for their easy methods to get the output. Output have been produced as per their expectation but it resulted in the short span of life. As days goes by the data get started to ruptured as we cannot store and maintain

\footnotetext{
${ }^{1}$ J. Suthanthara Raja Pushpa, PG Scholar, Dept of CSE, Panimalar Engineering College, Chennai E-mail: pushpastarmalar@gmail.com
} 
the vast amount of electronic data.A tabular format of all the techniques learnt and understood thus far have been computed for ease of use. Some methodology has some defects which will be resulting on low accuracy. Each method adopted have used various kinds of algorithm and steps to yield a better result. Some may be of same techniques but to get better accuracy than the previous findings, they have been adopted. Their drawbacks have been computed through which they have lost their accuracy when competing with others. These drawbacks are most common in some kind of papers as they will be using similar algorithms.

\section{Related works}

Works including various techniques are taken into consideration. Methodology like MLT (Machine Learning Techniques) and SVM are used in some papers but they do not have the desired output. Thus, the researchers moved to Image processing technique. Here the image obtained have been processed to yield the accurate image. These images get ruptured as days goes by as there is no separate method to store and maintain them at protected cost.Machine learning technique have been used to find the vehicle that breaks the law and this method made the simple structure of the system into a complex one. They do not provide an accurate result and the researchers spent their time in other domains like blockchain, license plate detection, etc. Ensemble learning also provide the least accuracy and thus cannot be adopted for the vast area of the network and to put forward for public use.

Intelligent vehicle tracking system have a robot developed and featured for the specific action. This root runs behind the vehicle that is assigned to track and thus to have an activated response from the user. This method was effective to be implemented in public. But the robot that runs behind the targeted vehicle is tend to get crashed or damaged by the vehicle that comes behind them. Thus, this method also faced a failure process. HSV (Hue Saturation Value) technique is implemented in some papers. But when the climate changes this gets affected as the human cannot control the nature. They get blurred and do not provide the result with satisfactory solution. Moreover, they get damaged in weather and the data stored are lost. This system has weak protected feature and thus cannot be implemented for public use in a long period of time as they get damaged by the natural calamities.

RFID (Radio Frequency Identifier) plays a vital role in this developing project and have many advantages in this technique. They can be installed anywhere and are easy to maintain in this vast area of network. Both the RFID sender and receiver and fixed in the selected spot and are connected to the centralized server. The server acts as a connectivity to detect the charges from the client's wallet. The database has all the records of the individual user and keeps track of the crime count in their system.

Table 1. Method adopted so far and their accuracy and drawbacks which paved the way for the emergence of new methodology

\begin{tabular}{cccc}
\hline S: NO & METHODOLOGY & ACCURACY & DRAWBACKS \\
1 & IOT & $95 \%$ & $\begin{array}{c}\text { Hardware units does } \\
\text { not function properly when } \\
\text { there is an error. } \\
\text { Image takes gets }\end{array}$ \\
& Image Processing & $80 \%$ & Imaptured as days goes by. \\
\hline
\end{tabular}




\begin{tabular}{|c|c|c|c|}
\hline & & & \multirow{3}{*}{$\begin{array}{c}\text { Miscommunication } \\
\text { leads to the confusion state } \\
\text { of the vehicle and the } \\
\text { monitoring end. } \\
\text { The least method used } \\
\text { as they have various error in } \\
\text { working. }\end{array}$} \\
\hline 3 & V2V & $30 \%$ & \\
\hline 4 & Blockchain & $25 \%$ & \\
\hline 5 & License plate detection & $67 \%$ & $\begin{array}{l}\text { Image dets destroyed } \\
\text { or get faded. }\end{array}$ \\
\hline 6 & Surveys & $70 \%$ & $\begin{array}{l}\text { Statistics gives the } \\
\text { desired result in theory but } \\
\text { not in practical. }\end{array}$ \\
\hline 7 & Video capturing & $87 \%$ & $\begin{array}{l}\text { Videos gets damages } \\
\text { after some years without } \\
\text { proper maintenance. }\end{array}$ \\
\hline 8 & HSV & $90 \%$ & $\begin{array}{l}\text { They get damaged to } \\
\text { climate changes which } \\
\text { cannot be fixed in human } \\
\text { end. }\end{array}$ \\
\hline 9 & Gray scaling & $86 \%$ & $\begin{array}{l}\text { Slicing out to get } \\
\text { perfect image leads to data } \\
\text { loss. }\end{array}$ \\
\hline 10 & On-board unit & $75 \%$ & $\begin{array}{c}\text { Possibilities of } \\
\text { malfunction on running. }\end{array}$ \\
\hline 11 & RFID & $89 \%$ & $\begin{array}{l}\text { Physical damage to the } \\
\text { RFID tags is possible. }\end{array}$ \\
\hline 12 & Hidden Markov model & $60 \%$ & $\begin{array}{l}\text { Does not give desired } \\
\text { solution to problem } \\
\text { statement. }\end{array}$ \\
\hline 13 & Machine learning & $40 \%$ & $\begin{array}{l}\text { Makes the system more } \\
\text { complex. }\end{array}$ \\
\hline 14 & Tracking robot & $30 \%$ & $\begin{array}{c}\text { Robots can get } \\
\text { damaged while under work. }\end{array}$ \\
\hline 15 & SVM & $54 \%$ & $\begin{array}{l}\text { No desired output is } \\
\text { obtained. }\end{array}$ \\
\hline 16 & Incident detection & $70 \%$ & $\begin{array}{l}\text { Physical damage to the } \\
\text { system lead to the faulty } \\
\text { state }\end{array}$ \\
\hline 17 & Ensemble learning & $30 \%$ & $\begin{array}{l}\text { Does not provide the } \\
\text { required result }\end{array}$ \\
\hline 18 & $\begin{array}{l}\text { Probabilistic neural } \\
\text { network }\end{array}$ & $15 \%$ & $\begin{array}{l}\text { Complexity of the } \\
\text { system is high. }\end{array}$ \\
\hline 19 & VANET & $45 \%$ & $\begin{array}{l}\text { Not applicable to all the } \\
\text { areas. }\end{array}$ \\
\hline 20 & Behavior analysis & $40 \%$ & Not predictable \\
\hline
\end{tabular}

\section{Methodology}

Proposed project consists of RFID tag that have both RFID receiver and RFID sender. Streets and paths that are required to be monitored are to be fitted with RFID receiver to track and scan the vehicles. The vehicle has to be attached with the RFID tag. This RFID tag have some unique features that contain the complete details provided by the user in initial stage. 
The architecture diagram shows the pathway of the project that is being developed. They have separate sections for detection of vehicle in parking area or not, penalty detection, cancellation process, etc. They have a centralized server that serves as communication bridge among the user and the system. The information collected from the user and the activities done by the mobile client are being recorded completely in that particular RFID tag. Each RFID tag have unique numbers.

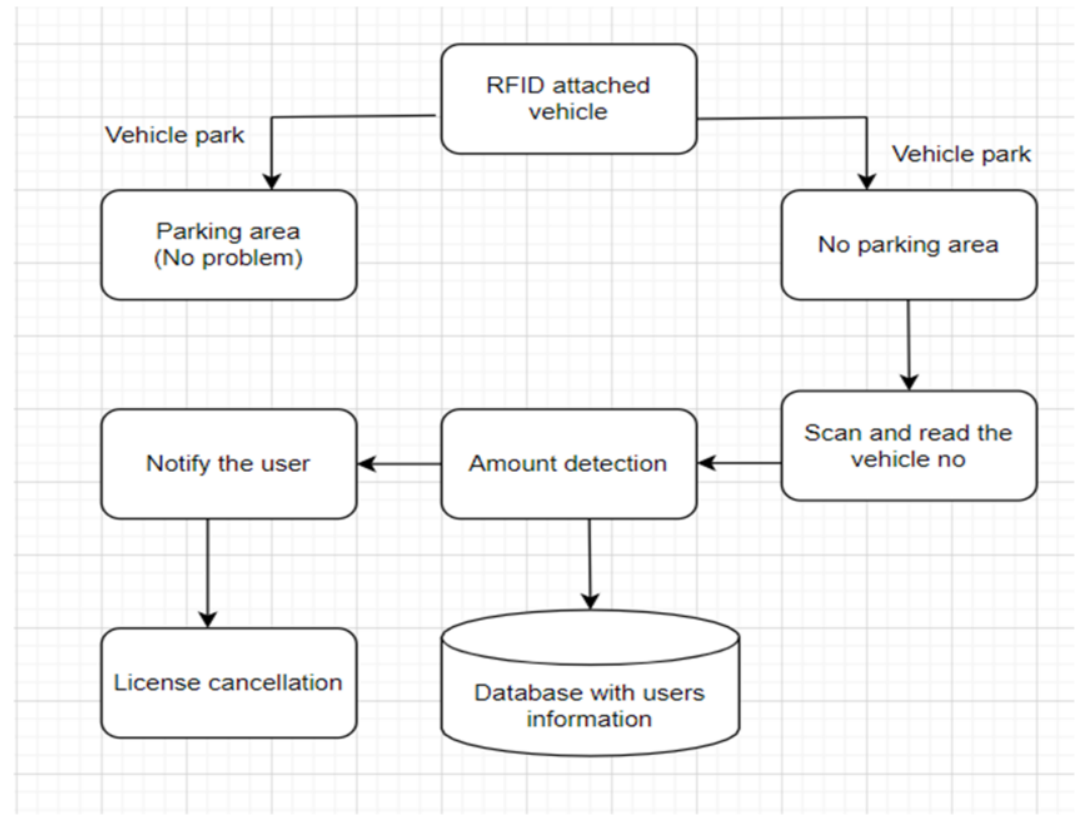

Figure 1. Architectural diagram

Maximum of three excuse is provided in this system. When the client takes up more than three excuse this system gets informed and will lead the way to cancel the license of the mobile client. Even when the mobile client does not respond to the alert the police will take action and will go and inspect the mobile client's resident in person which has been provided in the registration phase. This reduces the malversation to high impact and reduce the manual inspection of the cops and other process. This can be fitted in all the public area where there is a high risk of congestion during peak hours. They provide online monitoring and tracking of the vehicles which is ease of use and to have a great work line in public.

\section{Conclusion and future work}

Thus, a system using RFID has been developed and been implemented in the needy area. This method helps in identifying the vehicle that breaks the law in order and being a main reason for congestion. That particular vehicle has to be scanned using RFID receiver and get the required details that are stored in the database which is the centralized server. The details that are registered in the first phase have to be kept safe as that will be responsible for all the activities of the mobile client. Cancellation and 
penalty have to be taken care at the police end as they have a separate section for that particular monitoring system. This method has produced better results when compared to many other systems and have a reliable feature which will be of great help in the near future. This method helps to a great extent and provide a helping hand in eradication of the malversation in traffic field that gain trust and respect among public to police.

\section{References}

[1] Y. Gu, Z. Qian, and F. Chen, From Twitter to detector: Real-time traffic incident detection using social media data, Transportation Research Part C: Emerging Technologies, vol. 67, pp. 321-342, 2016.

[2] J. D. G. Paule, Y. Sun, and Y. Moshfeghi, On fine-grained geo- localization of tweets and real-time traffic incident detection, Information Processing \& Management, vol. 56, no. 3, pp. 1119-1132, 2019.

[3] Zhang.Z, Q. He, J. Gao, and M. Ni, A deep learning approach for detecting traffic accidents from social media data,Transportation Research Part C: Emerging Technologies, vol. 86, pp. 580-596, 2018.

[4] Dabiri.S and K. Heaslip, Developing a Twitter-based traffic event detection module using deep learning architectures, Expert Systems with Applications, vol. 118, pp. 425-439, 2019.

[5] Abuelela.M, S. Olariu, M. Cetin, and D. Rawat, Enhancing automatic incident detection using vehicular communications, in 2009 IEEE 70th Vehicular Technology Conference Fall, pp. 1-5, IEEE, Anchorage, AK, USA, 2009.

[6] J. Lu, S. Chen, W. Wang, and B. Ran, Automatic traffic incident detection based on nFOIL, Expert Systems with Applications, vol. 39, no. 7, pp. 6547-6556, 2012.

[7] R.Vidhya, K.Valarmathi.Automatic Monitoring of Hydroponics System Using IoT. Lecture Notes on Data Engineering and Communication Technologies, volume 35, pp 641-648, 2020

[8] Dhivya, K Valarmathi .IoT Based Smart Electric Meter.Lecture Notes on Data Engineering and Communication Technologies, volume 35, pp 1260-1269, 2020.

[9] R. Wang, S. Fan, and D. B. Work, Efficient multiple module particle filtering for joint traffic state estimation and incident detection, Transportation Research Part C: Emerging Technologies, vol. 71, pp. 521-537, 2016.

[10] M. Fogu, P. Garrido, F. J. Martinez, J. C. Cano, C. T. Calafate, and P. Manzoni, Automatic accident detection: assistance through communication technologies and vehicles, IEEE Vehicular Technology Magazine, vol. 7, no. 3, pp. 90-100, 2012.

[11] S.V. Ruphitha et.al.Management of Major Postpartum Haemorrhage by using Zigbee protocol - A Review .2021 6th International Conference on Inventive Computation Technologies (ICICT) (DOI: 10.1109/ICICT50816.2021.9358757)

[12] Ambeth Kumar.VD . Novel Wireless Sensing System For The Welfare Of Sewer Laborers. Healthcare Technology Letters (IET) Volume 5, Issue 4, p. 107 -112, 2018

[13] Ambeth Kumar.V.D, G.Saranya , D.Elangovan, V.RahulChiranjeevi, V.D.Ashok Kumar.IOT Based Smart Museum Using Wearable Device. Lecture Notes in Networks and Systems, Vol.55, pp: 33-42, 2018

[14] Ambeth Kumar.V.D andDr.M.Ramakrishan.Footprint Based Recognition System. in the month of April for the International Journal Communication in Computer and Information System, Volume 147, Part 3, 358-367, DOI: 10.1007/978-3-642-20573-6_63, April 2011

[15] Ambeth Kumar.V.D (2017).Efficient Routing for Low Rate Wireless Network a Novel Approach. International Journal of Image Mining, Vol. 2, Nos. 3/4, 2017, 2017

[16] Hema Kumar.S, J.UdayKiran, V.D.AKumar, G.Saranya, Ramalakshmi V, "Effective Online Medical Appointment System", International Journal of Scientific \& Technology Research, Volume 8, Issue 09, September 2019, Pages 803 - 805.

[17] Ambeth Kumar.V.D, Dr.M.Ramakrishnan, V.D.Ashok Kumar and Dr.S.Malathi (2015).Performance Improvement using an Automation System for Recognition of Multiple Parametric Features based on Human Footprint. kuwait journal of science, Vol 42, No 1 (2015), pp:109-132.

[18] B.Akshaya, M.Rajendiran.Securing Documents Using Digital Certificate-A Review. International Journal of Research in Advent Technology (IJRAT), 2018 